\title{
Light Sensitivity and Visual Field Extension in Hemianopes Wearing Halfmoon Prismatic Sectors
}

\author{
Carlo Aleci ${ }^{1, *}$, Tiziana Usai ${ }^{1}$, Marzia Pai ola ${ }^{2}$ \\ ${ }^{1}$ Department of Ophthalmology, the Gradenigo Hospital, Turin, Italy \\ ${ }^{2}$ The NASI Institute, Moncalieri, Italy \\ *Corresponding author: carlo. aleci@gradenigo.it
}

Received May 29, 2013; Revised July 16, 2013; Accepted July 18, 2013

\begin{abstract}
A consistent body of literature maintains that the use of monocular sector prisms may enlarge the field of view of hemianopic patients, leading to a substantial improvement of their everyday life. Despite the potential interest, as far as we know clinical trials focusing on this last topic are few. Indeed, the effect of the monocular sector prisms on the whole extent of the binocular visual field and on the differential light sensitivity of the monocular ipsilateral visual field has not been fully investigated. This study aims at estimating the effect of a particular monocular prismatic sector, halfmoon shaped, placed on the carrier lens on the side of the loss, on the differential light sensitivity as well as on the binocular visual field extent in hemianopic patients. The only significant ameliorative finding is the reduction of the gradient of sensitivity between the blind and the responsive side of the monocular visual field in the eye under the prism. However, it fails to increase the differential light sensitivity of the eye fitted with the prism. Likewise, the extent of the binocular visual field did not change significantly, irrespective whether an adaptation period had occurred or not. In conclusion, our results suggest that the ameliorative effect in hemianopes provided by the of prismatic treatment depends on the enlargement of the field of view rather than on substantial enlargement of the visual field and/or on increased light sensitivity.
\end{abstract}

Keywords: hemianopia, visual field, differential light sensitivity, prismatic treatment, monocular sectors

Cite This Article: Aleci, Carlo, Tiziana Usai, and Marzia Paiola, "Light Sensitivity and Visual Field Extension in Hemianopes Wearing Halfmoon Pris matic Sectors.” American Journal of Medical and Biological Research 1, no. 3 (2013): 77-85. doi: 10.12691/ajmb r-1-3-4.

\section{Introduction}

Due to the wide representation of the visual pathway in the central nervous system, visual field defects and in particular homonymous hemianopias are a main consequence of cerebrovascular accidents and cerebral tumors [1]. It is reckoned that in about $20-30 \%$ of strokes the visual system is involved to a certain degree [2,3]. Patients suffering from this condition complain difficulty in navigation and driving, so that great effort has been made in the last 40 years to find optical devices able to expand their impaired impaired visual perception beyond the midline. In this respect the use of a narrow prism fit on one lens of the spectacles has been proposed since the seventies and its effectiveness has been evaluated in terms of field of view enlargement, as well as of everyday life improvement [4-11]. Such advantage (fully experienced after a period of adaptation) takes place from the peripheral diplopia (and related visual confusion) which occurs when the direction of gaze crosses the prism. In contrast to the binocular field of view, the enlargement of the binocular visual field is unexpected, since in primary position of gaze the prism would not be involved (Bowers et al, 2008). Yet, binocular visual field widening has been reported when monocular 15-40 $\Delta$ base-out sector prisms are placed on the blind hemifield $[4,9,12]$, probably as a result of the shift of the retinal projection from the blind onto the responsive region provided by the prism $[9,13,14,15,16]$. In this connection, as far as we know the reported binocular visual field en largement has not been examined in terms of whole extent of the perimetric map, but by measuring the distance of boundary of the blind side from the fixation point. Moreover, it has not been quantified in terms of differential light sensibility recovery when examining the visual field both in monocular and binocular conditions. Finally, so far scarce attention has been paid to the shape of the pris matic sector (with the only exception of Smith who suggested to cut out a hemicircle 1-1.5 mm wide from the centre of the prism to prevent central diplopia [10]. Therefore, in the current experiment a sector prism has been specifically designed and geometrically described. Its effect has been estimated not only on the binocular visual field of hemianopic patients but also in monocular conditions: in the first case a global and quadrant-to-quadrant analys is on the extent of the visual space has been performed, in the second condition differential light sensitivity, position of the vertical border between the blind and spared hemifield and change of the threshold gradient have been measured.

\section{Materials and Methods}




\subsection{Pris $m$ Design}

$3 \mathrm{M}$ Press-On ${ }^{\mathrm{TM}}$ prisms were used to design sectors to be cut and positioned on one lens of the patients' spectacle. The shape of the sector is inspired from previous studies $[4,9,10,17]$. As a result, a 20 - or 30 -dioptres halfmoonshaped prismatic sector (HPS), base along the convex profile, has been obtained. Its main characteristic is the slightly rounded section of the internal profile (i.e. facing the corneal limbus) so as to keep its inner border slightly away from the fixation point. This solution should prevent from central diplopia. In the appendix are reported the geometric details. The device was placed on the temporal or on the upper side of the carrier lens (base out), so that four different power/side combinations (C) have been tested:

$$
\begin{aligned}
& \rightarrow 20 \Delta \text { on the temporal side }\left(\mathrm{T}_{20}\right) \\
& \rightarrow 30 \Delta \text { on the temporal side }\left(\mathrm{T}_{30}\right) \\
& \rightarrow 20 \Delta \text { on the upper side }\left(\mathrm{U}_{20}\right) \\
& \rightarrow 30 \Delta \text { on the upper side }\left(\mathrm{U}_{30}\right) .
\end{aligned}
$$

\subsection{Positioning of the Prism}

Each sector (extent: $3.30 \mathrm{~cm}^{2}$ ) was placed so that its concave border was tangent to the corneal limbus, at the midpoint along the horizontal or vertical axis for the temporal and upper position, respectively (Figure 1).

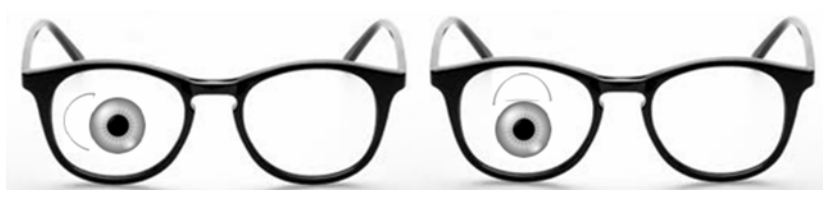

Figure 1. Appearance of the prismatic sector fitted on the lens on the side of the loss (in this case right)

Since, as already mentioned, the exact location is believed to be a material point [18], particular attention has been paid to this detail and the occurrence of even slight malpositioning of the glasses has been checked after an acquainting period following the prism placement.

\subsection{Sample}

Ten patients (6 males, 4 females) suffering from homonymous hemianopia as diagnosed at standard automated perimetry and resulting from post-stroke cerebral lesion as documented at CT and MNR were recruited by the Neuro-Ophthalmology Service of the

\begin{tabular}{|c|c|c|c|c|c|c|c|c|c|}
\hline $\begin{array}{l}\text { patie } \\
\text { nt }\end{array}$ & Sex & Age & Loss Side & $\begin{array}{l}\text { Cerebral } \\
\text { Lesion* }\end{array}$ & $\begin{array}{l}\text { Onset } \\
\text { (M) }\end{array}$ & $\begin{array}{c}\text { BCVA } \\
\text { R }\end{array}$ & $\begin{array}{c}\text { BCVA } \\
\text { L }\end{array}$ & $\begin{array}{l}\text { Refraction } \\
\text { (Sqh Eq) R }\end{array}$ & $\begin{array}{l}\text { Refraction } \\
\text { (Sqh Eq) L }\end{array}$ \\
\hline 1 & M & 57 & $\mathrm{~L}$ & O right & 2 & $36 / 60$ & $60 / 60$ & 3.5 & 1 \\
\hline 2 & $\mathrm{~F}$ & 75 & $\mathrm{~L}$ & $\mathrm{~T}+\mathrm{O}$ right & 36 & $48 / 60$ & $48 / 60$ & 4.25 & 4.5 \\
\hline 3 & M & 57 & $\mathrm{~L}$ & O right & 14 & $60 / 60$ & $60 / 60$ & -1.25 & -2 \\
\hline 4 & $\mathrm{~F}$ & 33 & $\mathrm{~L}$ & O right & 39 & $60 / 60$ & $60 / 60$ & -1.25 & -1.5 \\
\hline 5 & $\mathrm{~F}$ & 70 & $\mathrm{~L}$ & Mult right & 24 & $60 / 60$ & $60 / 60$ & -1.75 & -0.25 \\
\hline 6 & M & 52 & $\mathrm{~L}$ & FTP right & 84 & $60 / 60$ & $60 / 60$ & -2 & -3 \\
\hline 7 & M & 38 & $\mathrm{~L}$ & O right & 33 & $60 / 60$ & $42 / 60$ & 2 & -1.5 \\
\hline 8 & M & 70 & $\mathrm{~L}$ & O right & 13 & $60 / 60$ & $60 / 60$ & 0.75 & 1.25 \\
\hline 9 & M & 27 & $\mathrm{~L}$ & $\mathrm{~T}$ right & 8 & $60 / 60$ & $60 / 60$ & -0.5 & -0.5 \\
\hline 10 & F & 27 & $\mathrm{R}$ & O left & 20 & $60 / 60$ & $60 / 60$ & 0 & 0 \\
\hline $\begin{array}{l}\mathrm{ME} \\
\mathrm{AN}\end{array}$ & & 50.6 & & & 27.3 & $56 / 60$ & $57 / 60$ & 0.37 & -0.2 \\
\hline SD & & 18.3 & & & 23.3 & 0.13 & 0.11 & 2.2 & 2.1 \\
\hline
\end{tabular}
Ophthalmology Department at the Gradenigo Hospital of Turin (Table 1).

Table 1. Demographic and dinical data

Based on the current definition, a visual field defect is called hemianopic if the whole hemifield is depressed with a sharp separation along the vertical meridian (vertical step, VS) and without any other abnormal test locations that would obscure the homonymous pattern [19]. Homonymous hemianopia takes place when the impaired hemifield in both eyes are on the same side (right or left). In our cases the affected hemifield was characterised by a deep or absolute loss of the differential light sensitivity. The loss was on the right side in all patients but one (patient nb 10). The time of onset of neurological symptoms varied from 2 to 84 months. The age in the sample ranged from 27 to 75 years (median 54.5). Monocular BCVA was in the majority of cases 60/60. Exclusion criteria were refractive defects (spherical equivalent) $\geq \pm 5$ diopters, ophthalmological diseases, intraocular pressure $>18 \mathrm{mmHg}(\mathrm{G})$ or inheritance for glaucoma, strabismus, oculomotor nerve palsies, amblyopia, diabetes, systemic therapies able to induce visual field defects, poor cognitive state as assessed at Mini Mental State Examination [20] and poor cooperation. All subjects were able to walk normally without any aid. One patient (n. 6) had left arm palsy. None suffered from superior limbs palsy. All patient demonstrated foveal stable fixation at Cuppers'visuscope.

Subjects underwent a preliminary complete ophthalmological examination, including slit lamp inspection, retinoscopy, applanation tonometry, visual acuity measurement, pupillary reflexes and ocular movement assessment. None of the recruited subjects referred visual hallucinations, even if this symptom develops in about one eighth of the hemianopic patients [21].

We certify that the research followed the tenets of the Declaration of Helsinki, that informed consent was obtained from the subjects after explanation of the nature 
and possible consequences of the study, and that all applicable institutional and governmental regulations concerning the ethical use of human volunteers were followed. This study has been approved by the institutional review board of the Ophthalmology Department of the Gradenigo Hospital.

\subsection{Study Design}

Due to their clinical condition, all patients were accustomed to visual field testing. As a preliminary assessment, to confirm the presence of the hemianopia and to ensure the collaboration of the patient was good, every subject underwent a standard automated perimetry (SAP) in monocular conditions by an Octopus 1-2-3 perimeter (Haag-Streit, Bern, Switzerland), program 32x, which tests $30^{\circ}$ on each side of the fixation point (76 locations within on a $6^{\circ}$-spaced grid, stimulus size $0.43^{\circ}$ ). Examinations were considered reliable if reliability factor (RF) was lower than $25 \%$ and false positive errors were less than $10 \%$. In addition, monocular kinetic perimetry (MKP) by means of Goldmann perimeter (Haag-Streit, Bern, Switzerland) was obtained during the same session, using a Goldmann stimulus, size V/4e. The target was moved linearly from the periphery toward the fixation point with constant speed of about $4 \mathrm{deg} / \mathrm{sec}[22,23]$. To ensure the constant and correct speed rate of target, a metronome connected to the operator via earphones was employed.

In performing kinetic perimetry the technician was instructed to retest the sensibility along the same meridian whenever a lack of fixation was supposed to occur or if she was not sure of the answer given by the patient. Right and left eyes were examined in random order.

Within about a week from this preliminary assessment (T0), patients were called and underwent binocular kinetic perimetry (BKP) by means of a Goldmann perimeter. The subject was required to keep his head firmly on a chin rest, positioned on the side of the spared hemifield. In fact, the binocular visual field mapping derived by the non-central position of the chin rest and is comparable to the outcome obtained with the head in central position [9]. Later on, one of the four HPS comb inations (randomly chosen) (C1) was fitted on the glasses of the subject and after about 30 minutes BKP was newly performed ("no adaptation BKP”). The patient was then dismissed. He was recommended not to remove the $\mathrm{C} 1$ from $\mathrm{h}$ is lens and to wear the spectacle with the prism as much as possible. Instead, he was urged not to wear the prism when driving.

After 3 weeks (T1), patients with the C1 underwent BKP (“adaptation BKP”) and monocular SAP examining both the eye with the $\mathrm{C} 1$ and (as a control) the contralateral one. The order of the two exams and the order of the examined eye at SAP was randomized.

After about 1 hour, C1 was removed and a second combination (randomly chosen) (C2) was fitted on the spectacle of the subject; then, after about 30 minutes, BKP was newly performed.

The same procedure was followed after 6 weeks (T2, C3), 9 weeks (T3,C4) and 12 weeks (T4) (Figure 2).

Results were thus collected and statistical analysis was performed.

The visual field examination took place in a dimmed room (average illumination: 1 lux) and was conducted by the same, skilled operator. Time after time she was unaware of on the combination placed on the glasses.



Figure 2. Design of the study

\section{Results}

\subsection{Monocular Automated Visual Field}

The results from monocular SAP at baseline are shown for every subject in Table 2 .

The improvement in monocular visual field by wearing the prismatic sectors have been assessed in terms of:

- reduced mean defect in the whole visual field and in the affected hemifield.

- reduced difference of sensibility between normal and affected hemifield.

- shift of the spared hemifield boundary toward the blind region.

- smoothing of the sensitivity gradient across the vertical step.

Table 2. Visual field at baseline expressed as Mean Defect (MD)

\begin{tabular}{|c|c|c|c|}
\hline Patient & $\begin{array}{c}\text { Whole } \\
\text { Field }\end{array}$ & $\begin{array}{c}\text { Affected Hemifield } \\
\text { Superior quadrant }\end{array}$ & $\begin{array}{c}\text { Affected Hemifield } \\
\text { Inferior Quadrant }\end{array}$ \\
\hline 1 & 9.7 & 15.6 & 25.1 \\
\hline 2 & 16.2 & 23.9 & 21.3 \\
\hline 3 & 11.7 & 22.7 & 19.3 \\
\hline 4 & 12.9 & 22.5 & 27.9 \\
\hline 5 & 7.1 & 20.4 & 14.6 \\
\hline 6 & 12.4 & 23.6 & 27.2 \\
\hline 7 & 11.3 & 23.2 & 22.5 \\
\hline 8 & 9.1 & 10.9 & 25.5 \\
\hline 9 & 12.3 & 22.7 & 18.6 \\
\hline 10 & 13.5 & 25.8 & 28 \\
\hline Mean & 11.6 & 21.1 & 23 \\
\hline SD & 2.5 & 4.5 & 4.5 \\
\hline Median & 12.3 & 22.7 & 22.5 \\
\hline Range & $7.1-16.2$ & $10.9-25.8$ & $14.6-28$ \\
\hline
\end{tabular}


After wearing the 4 prismatic combinations, mean MD referred to the whole field and to the superior and inferior quadrant of the affected hemifield did not differ significantly (one-way ANOVA $(F=0.98): p=0.42$; Kruskal-Wallis $(\mathrm{KW}=3.22)$ : $\mathrm{p}=0.52$; one-way ANOVA $(\mathrm{F}=0.51): \mathrm{p}=0.72$ respectively).

To further investigate this point, the ratio between the light sensitivity depression across the visual field before and after wearing the combinations has been computed as Change Ratio $\left(\mathrm{CR}=\mathrm{MD}_{\text {bas }} / \mathrm{MD}_{\text {prism }}\right)$. The analysis has been performed on the MD global score and on the partial scores relative to the superior and inferior quadrant of the affected hemifield. Even though mean CR turned out to be positive in every pris m condition (i.e. reduced mean defect when wearing the pris m), such an improvement resulted not significant (Kruskal-Wallis $[\mathrm{KW}=1.40]$ : $\quad \mathrm{p}=0.70$; $[K W]=2.59: p=0.45 ;[K W]=2.00: p=0.57$ for the total map, superior and inferior affected quadrant, respectively: Figure 3, left panel).

Thereby, no increase of differential light sensitivity is found in the visual field by wearing the prism sectors, irrespective of the type of combination. This finding is valid when considering the whole extent of the map or just the affected region.

Even in absence of an overall improvement of light sensitivity, due to the prismatic effect a shift of the

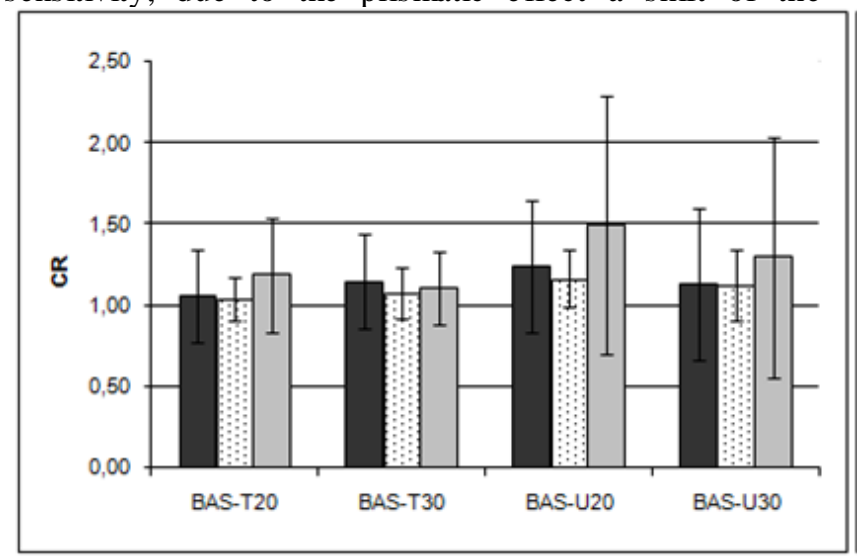

vertical step away from the fixation point might take place. To test this possibility, we have assumed that at each eccentricity along the vertical meridian a shift of the vertical step toward the blind region takes place if the threshold of the corresponding point located on the blind side of the midline turned out to be normal in the prismatic condition. In case the sensibility of the spared hemifield were depressed to a certain amount close to the midline, a vertical step shift is presumed to occur if the threshold of the point in the affected side of the vertical step has improved, matching at least the threshold value of the adjacent point in the spared side found in the no-prism condition.

Therefore, a point-to point analysis along the vertical meridian has been performed. The analysis expresses the results as a binary outcome (score $1=$ shift occurred at that locus; score $0=$ shift not occurred at that locus) and a vertical shift score (VSS) is derived from the ratio between the number of recovered loci and the total number of examined loci. So, VSS score $=1$ means that the vertical step shift has occurred for each locus along the midline, VSS score $=0$ means that no shift has occurred at all.

Mean VSS score was $0.24( \pm 0.12)$ for $\mathrm{T}_{20}, 0.13( \pm 0.07)$ for $\mathrm{T}_{30}, 0.13( \pm 0.11)$ for $\mathrm{U}_{20}$ and $0.12( \pm 0.12)$ for $\mathrm{U}_{30}$ (Figure 3, right panel).

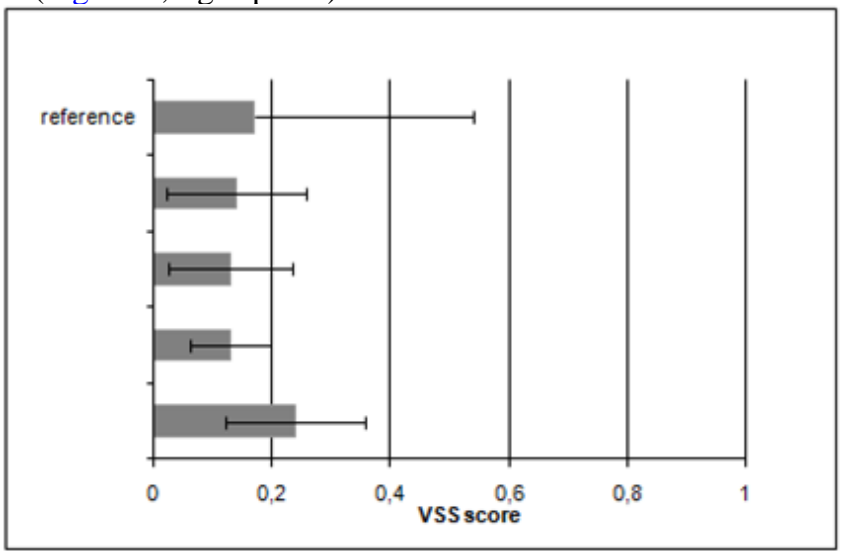

Figure 3. Change of the sensitivity of the monocular perimetric map in the four prismatic conditions. Left panel: change ratio (CR) in the 4 prismatic conditions. Black: whole hemifield; dotted: superior quadrant (affected hemifield); gray: inferior quadrant (affected hemifield); right panel: effect of the prismatic sectors on the vertical step shift computed as the proportion of normalized loci with wearing the prism.

In order to establish if the VSS scores obtained in prismatic conditions are statistically significant or simply due to chance, a global VSS reference score has been estimated by computing in the patients the number of apparently improved loci in the maps from the contralateral eye (i.e. without the prism) at the preliminary assessment and at T1-T4. The VSS reference score, which is therefore assumed to be due to chance, resulted to be 0.17 , that is to say higher compared to the VSS score in all prismatic conditions but for the $\mathrm{T}_{20}$ combination. However, even in this last case the difference was not statistically significant (unpaired t- test, Welch corrected: $\mathrm{p}=0.11$ ).

Despite the absence of significant improvement of sensibility and of vertical step shift, the pris m sectors may affect the gradient of sensitivity across the VS, making less sharp the limit between the responsive and the non responsive hemifield.

To ascertain this last point, the profile of light sensitivity extending horizontally from the midline till to 12 deg toward the normal hemifield and 18 deg toward the affected region $(+12 \rightarrow-18 \mathrm{deg})$ was computed via a pointto-point analysis across each vertical meridian for each prism combination. The sensitivities reported at each eccentricity along the horizontal meridian in the perimetric maps of the patients have been averaged with the upper and lower values across the correspondent vertical meridian so as to obtain for each patient the general trend of sensibility from the non responsive to the responsive hemifield. The ten trends have been therefore averaged in order to compute the mean gradient of sensibility for each of the four experimental conditions.

The main effect of pris m comb ination was significant at $-6 \operatorname{deg}(\mathrm{F}=9.97, \mathrm{p}<0.01)$ and $-12 \operatorname{deg}(\mathrm{F}=9.74, \mathrm{p}<0.01)$. Tukey-Kramer multiple comparisons test showed that $\mathrm{U}_{20}$ and $U_{30}$ were effective in improving light sensitivity at 6 deg of eccentricity on the blind side of the vertical step (q $(5.27)=8.46, p<0.01)$ and that for $\mathrm{U}_{20}$ such effect extended up to $12 \mathrm{deg}$ in the affected hemifield (q (5.27)= 8.51, $\mathrm{p}<0.01$ : Figure 4). 

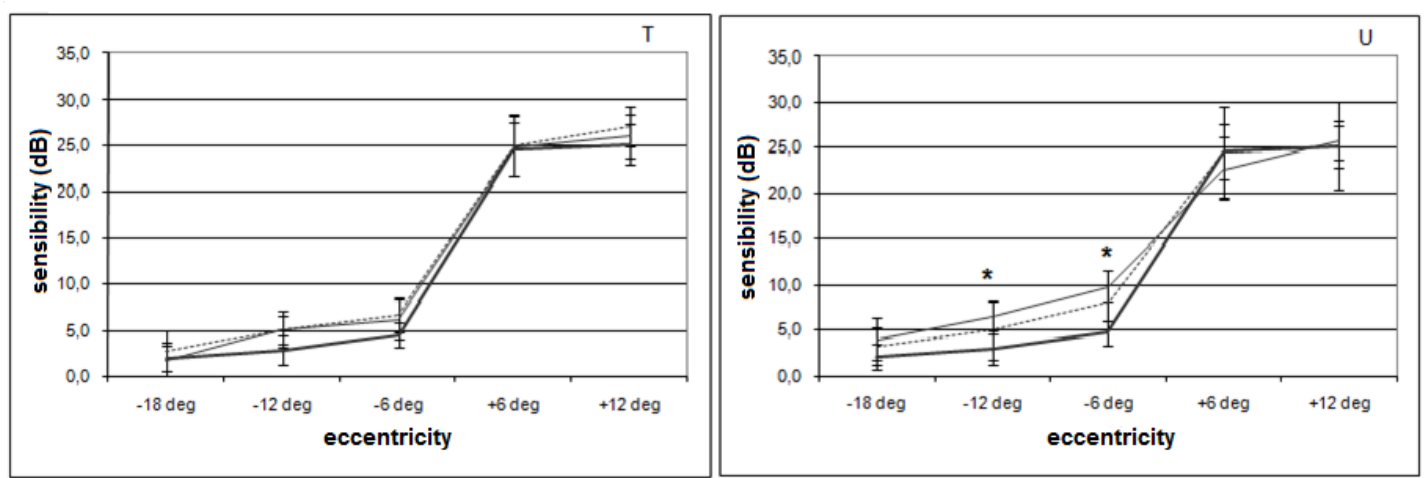

Figure 4. Effect of the prismatic combinations on the sensitivity gradient across the vertical step. Along the horizontal axis negative values refer to the blind hemifield. Left:temporal sect ors; right: upper sectors. Thick line: basal; dotted line: 30 diopters; thin line: 20 diopters. ${ }^{*}=\mathrm{p} \varangle 0.01$

In summary, the use of the SSS has no effect in improving the mean sensitivity in the monocular central visual field and across the hemianopic region, nor does it enlarge the normal area by moving its boundary toward the blind one. In monocular conditions the only ameliorative result is a significant improvement of the sensitivity gradient extending till to 12 deg along the vertical midline when pris matic sectors are placed in the upper position.

\subsection{Binocular Manual Visual Field}

The extent of the binocular visual field as assessed by BKP has been estimated before and after the positioning of the sectors. The analysis was performed on the whole extent of the map and per each quadrant of the affected and spared side. Once collected, the perimetric diagrams were digitalized and the total area subtended by the isopter as well as in each single quadrant (superior/inferior blind and superior/inferior affected), were computed by means of a mathematical software (Mat Lab (www.mathworks.it)).

Compared to the basal conditions, when wearing the four prism combinations the binocular visual field turned out to be slightly wider. However such apparent improvement, which involved both the total extent and the single quadrants before and after the adaptation period, did not reach the statistical significance (Table 3 and Figure 5).

Table 3. Binocular visual fieldextent before and after adaptation to prismatic sectors: comparison with the basal

\begin{tabular}{|c|c|c|c|c|c|c|c|c|c|}
\hline & \multicolumn{4}{|c|}{ Before Adapt ation } & & \multicolumn{4}{|c|}{ After Adaptation } \\
\hline Whole VF & Basal & $\mathrm{T} 20$ & T30 & $\mathrm{U} 20$ & U30 & $\mathrm{T} 20$ & T30 & U20 & U30 \\
\hline mean & 77.04 & 81.94 & 92.46 & 86.48 & 86.25 & 91.45 & 92.42 & 88.51 & 82.40 \\
\hline sd & 18.97 & 16.48 & 16.84 & 10.45 & 21.17 & 30.62 & 16.43 & 17.72 & 14.83 \\
\hline $\mathrm{p}$ & \multicolumn{5}{|c|}{ One-way ANOVA $p=0.4$} & \multicolumn{4}{|c|}{ One-way ANOVA $p=0.30$} \\
\hline Blind Sup Quadr & Basal & T20 & T30 & $\mathrm{U} 20$ & U30 & T20 & T30 & $\mathrm{U} 20$ & U30 \\
\hline mean & 2.82 & 4.82 & 6.29 & 6.25 & 9.96 & 5.82 & 5.61 & 7.77 & 6.77 \\
\hline $\mathrm{sd}$ & 2.67 & 3.18 & 4.82 & 3.02 & 9.27 & 5.04 & 3.37 & 5.65 & 4.79 \\
\hline median & 2,11 & 5,33 & 5,37 & 5,49 & 6,11 & 4,46 & 4,87 & 6,03 & 6,01 \\
\hline range & $0-6,76$ & $0,16-7,7$ & $0,6-14,1$ & $3,3-12,0$ & $1,2-27$ & $0,8-14,9$ & $2,3-13,3$ & $0,9-17,5$ & $1,2-15,9$ \\
\hline $\mathrm{p}$ & \multicolumn{5}{|c|}{ Kruskal-Wallis $\mathrm{p}=0.14$} & \multicolumn{4}{|c|}{ One-way ANOVA $p=0.2$} \\
\hline Blind Inf Quadr & Basal & T20 & T30 & U20 & U30 & T20 & T30 & $\mathrm{U} 20$ & U30 \\
\hline mean & 3.83 & 4.81 & 5.72 & 6.05 & 3.40 & 6.43 & 7.04 & 6.09 & 3.14 \\
\hline sd & 6.04 & 6.33 & 8.51 & 7.07 & 3.21 & 9.13 & 7.84 & 7.76 & 3.02 \\
\hline median & 2,20 & 3,53 & 3,44 & 5,80 & 3,09 & 2,44 & 4,54 & 3,75 & 2,05 \\
\hline range & $0-4,39$ & $0-21$ & $0-27,5$ & $0-22,4$ & $0-9,2$ & $0-28$ & $0-25,3$ & $0-25,1$ & $0-7,7$ \\
\hline $\mathrm{p}$ & \multicolumn{5}{|c|}{ Kruskal-Wallis $\mathrm{p}=0.83$} & \multicolumn{4}{|c|}{ Kruskal-Wallis $\mathrm{p}=0.72$} \\
\hline Spared Sup Quadr & Basal & T20 & T30 & U20 & U30 & T20 & Т30 & $\mathrm{U} 20$ & U30 \\
\hline mean & 29.00 & 30.41 & 33.43 & 29.42 & 29.26 & 33.57 & 33.46 & 30.43 & 29.44 \\
\hline sd & 8.39 & 6.79 & 7.68 & 6.79 & 7.44 & 7.72 & 7.01 & 8.00 & 7.07 \\
\hline median & 23,95 & 28,59 & 36,06 & 30,11 & 29,83 & 35,83 & 35,08 & 29,91 & 29,51 \\
\hline range & $19,6-41$ & $22,0-39,7$ & $21,2-40,9$ & $22,5-41,8$ & $18,7-39,8$ & $21,6-43$ & $21,3-42,5$ & $18,9-41,5$ & $21,0-37,1$ \\
\hline $\mathrm{p}$ & \multicolumn{5}{|c|}{ Kruskal-Wallis $\mathrm{p}=0.67$} & \multicolumn{4}{|c|}{ Kruskal-Wallis $\mathrm{p}=0.57$} \\
\hline Spared Inf Quadr & Basal & T20 & Т30 & U20 & U30 & T20 & T30 & U20 & U30 \\
\hline mean & 41.30 & 41.87 & 44.68 & 44.75 & 43.56 & 45.62 & 46.31 & 44.22 & 43.05 \\
\hline sd & 9.95 & 8.48 & 7.79 & 5.23 & 7.32 & 8.87 & 8.90 & 7.68 & 6.98 \\
\hline median & 39,04 & 38,91 & 42,92 & 44,74 & 41,35 & 48,94 & 42,32 & 44,95 & 43,09 \\
\hline range & $26,3-54,4$ & $30,2-56,1$ & $34,9-57,9$ & $37,6-55,5$ & $35,3-57,9$ & $33,2-56,6$ & $38,3-66,2$ & $34,2-56,2$ & $34,9-52,3$ \\
\hline $\mathrm{p}$ & \multicolumn{5}{|c|}{ One-way ANOVA $p=0.83$} & \multicolumn{4}{|c|}{ Kruskal-Wallis $\mathrm{p}=0.79$} \\
\hline
\end{tabular}




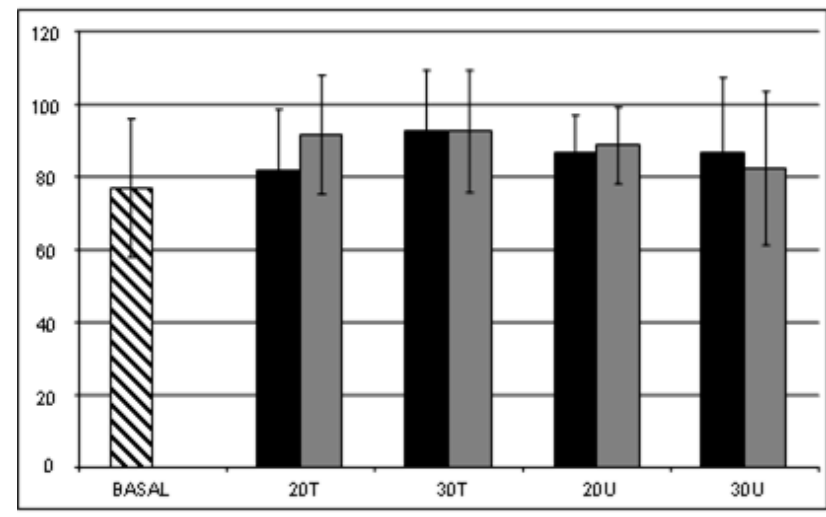

Figure 5. Binocular visual field enlargement in the four prismatic combinations. Black: before adaptation; gray: after a 3-week period of adaptation On the ordinate is reported the area of the residual vision on the visual field map $\left(\mathrm{cm}^{2}\right)$. Bars refer to standard deviation
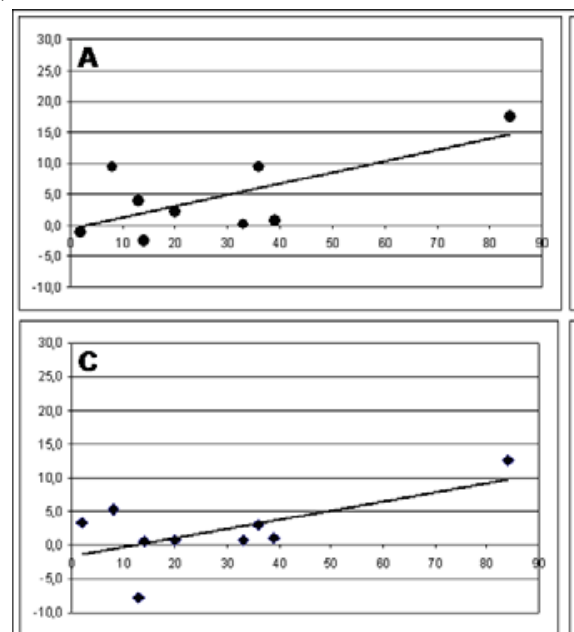

Figure 6. Correlation between onset time and spared hemifield enlargement in the four prismatic combinations after adaptation. A: $T_{20}$, B: $T_{30}$, C: $U_{20}$, D: $\mathrm{U}_{30}$. Abscissa: onset time (months); ordinate: field enlargement $\left(\mathrm{cm}^{2}\right)$

Even if the average differences are not statistically significant, when wearing the pris ms the binocular visual field improved in the majority of patients, both before and after the adaptation period (before adaptation: T20: 66\%, T30:100\%, U20: 89\%, U30: 87\%; of patients; after adaptation: T20: 89\%, T30: 77\%, U20: 89\%, U30: 87\% of patients).

In conclusion, in this second part of the study a slight enlargement of the binocular visual field with wearing the prismatic sectors is found in the majority of patients, and the longer the time passed from the onset of the cerebral accident, the greater is the ameliorative effect on the spared hemifield. However, on average the improvement did not result statistically significant.

\section{Discussion}

After open-angle glaucoma, stroke is stated to be the second cause of persistent visual field impairment, which is in turn associated with reduced enjoyment of daily activities, fall accidents [24] and depressive conditions [25]. Moreover, such a visuoperceptive impairment may hamper the rehabilitation program $[26,27]$ so that according to Kaplan \& Hier [28] visual field loss, if present, should be considered as important as hemiparesis when treating such patients.

According to a consistent body of literature, pris matic treatments look to be effective in improving the visual
Patients' age does not correlate with the change of BKP after the adaptation period. On the contrary, a correlation is found between the interval from the onset of the cerebral accident and the change of the extent of the spared hemifield after 3 weeks of adaptation to the prismatic sectors: indeed, this correlation resulted statistically significant in the $\mathrm{T}_{20} \mathrm{~T}_{30}$ and $\mathrm{U}_{30}$ combinations and close to significant for $\mathrm{U}_{20}(\mathrm{r}=0,68: \mathrm{p}=0.04 ; \mathrm{r}=0,71$ : $\mathrm{p}=0.03 ; \mathrm{r}=0,76: \mathrm{p}=0.02 ; \mathrm{r}=0,62: \mathrm{p}=0.06$ respectively) (Figure 6).

The independent analysis of the upper and inferior spared quadrant revealed that the major contribute to such a trend comes for the latter: in fact, the statistical significance of the correlation raises if the analysis is restricted to the inferior quadrant $(r=0.80: p=0.008$; $r=$ 0.83: $p=0.004 ; r=0.77: p=0.01 ; r=0.79: p=0.01$ for $\mathrm{T} 20$, T30, U20 and U30, respectively) whereas it disappears if the analysis is limited to the superior one.
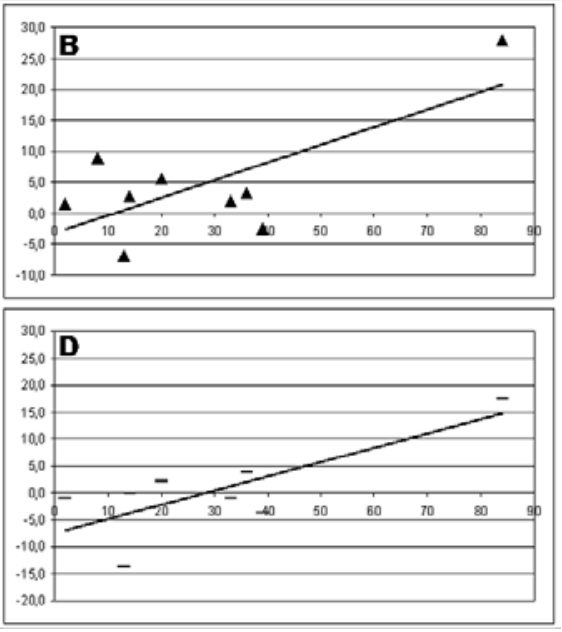

function of hemianopic patients. In particular, the use of narrow pris ms mounted on one lens of the spectacles has been proposed since the seventies and its usefulness has been evaluated in terms of field of view enlargement as well as of everyday life improvement. Indeed, such monocular prismatic sectors fit on the side of the loss seem to be able to enlarge the visual boundaries up to 10 deg $[4,5,6,7,8,10,11,12]$ or $20-22$ deg beyond the midline [9].

This effect is claimed to depend on the shift of the visual stimulation directed toward the blind region onto the responsive one in the eye fitted with the prism $[9,13,14,15,16]$. As a consequence of this diversion, two different stimuli fall on correspondent retinal elements, so that when viewing binocularly peripheral visual confusion is expected to occur immediately after the positioning of the prism; however after an adaptation period of at least one week [9], compensation based on the development of abnormal retinal correspondence takes place and the confusing stimulus is integrated into a "perceptually" univocal configuration [29]. In effect "visual awareness" is found to improve in this condition [6].

Peli tested the binocular visual field before and after placing a $40 \Delta$ base-out monocular sector prism on the upper and/or lower part of the spectacle and occupying its whole width [9]. According to his design, upper prism was placed on the side of the loss with its lower edge at the level of the sclerocorneal limbus. In this way he reported 
both at manual dynamic Goldmann perimetry and automated static perimetry (as evaluated by means of the Easterman test) a visual expansion by about 15-20 deg in 11 out of his 12 patients with homonymous hemianopia or quadrantanopia.

Giorg i et al. employed $40 \Delta$ Fresnel prism sectors fitted monocularly on the upper and lower surface of the lens on the side of the loss to rehabilitate 23 homonymous hemianopic patients. In line with the previous findings, by using Goldmann perimetry they found a binocular field expansion of $22 \mathrm{deg}$ along the upper and lower regions in all patients [4]. Similar results have been further reported by O'Neill et al [30] in 10 out of 12 hemianopic patients after fitting monocular sector prisms in accordance with the method described by Peli. Wearing oblique prism sectors on one lens on the side of the loss is recently found to be useful in reducing hazard when driving [31].

So far as we know, the effect of the monocular prismatic treatment has been generally measured in terms of amount of displacement of the scotomatous boundary away from the fixation point. To analyse more in depth this rehabilitative solution, in the current study the differential light threshold as assessed at monocular automated perimetry as well as the overall extension of the residual isle of vision at binocular kinetic perimetry has been estimated.

Even if the sector is placed with in the boundary of the scotomatous hemifield, it could enhance the borderline residual sensitivity provided its inner side is central enough : that is to say it could be able to move the stimuli directed onto the blind region toward the less compromised region of transition between the "seen" and the "non-seen". According to this scenario, an improvement of visual sensitivity in the eye fitted with the prism is expected to be measurable at monocular perimetry.

Yet, after positioning the halfmoon sector, no improvement was found in monocular conditions in terms of mean sensibility referred to the whole visual field or limited to the affected hemifield. Likewise, the sectors failed to move the boundary of the normal area (i.e. with normal sensitivity altogether) toward the blind region. Nonetheless, the 20-diopter sector placed on the upper side of the lens was found to be effective in reducing the
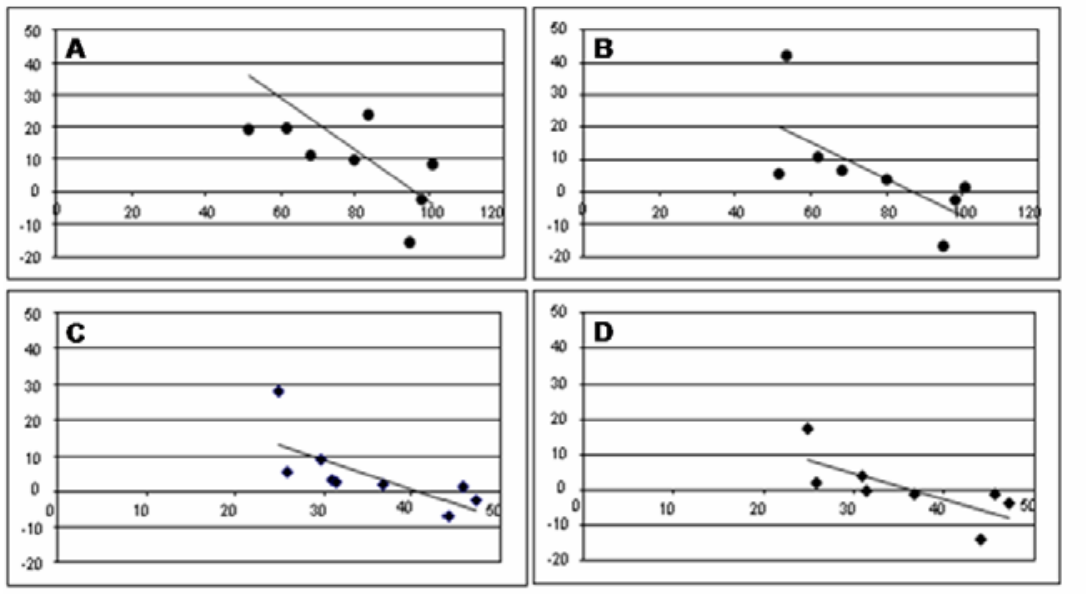

Figure 7. Correlation between whole visual field or spared hemifield at baseline and widening after prismatic adaptation. Upper panels: whole visual field extent at baseline. A: $T_{30}(r=-0.69, p=0.03)$; $B: U_{30}(r=-0.68, p=0.05)$. Lower panels: spared visual field extent at baseline. C: $T_{30}(r=-0$. 72, $\mathrm{p}=0.03)$; $\mathrm{D}: \mathrm{U}_{30}(\mathrm{r}=-0.73, \mathrm{p}=0.03)$. Abscissa: visual field extent at baseline $\left(\mathrm{cm}^{2}\right)$, ordinate: visual field widening after 3 weeks of adapt at ion. It can be noticed that the wider is the visual field at the baseline, the smaller the improvement after adaptation gradient between the spared and blind side of the monocular perimetric map. Thence, it is arguable that even though the influence of the sector effect is not so visual field, nor is it enough to advance the boundary of the normal side toward the blind area, nevertheless it serves to improve (but not normalize) light sensitivity right across the vertical responsive/blind limit as far as 12 degrees deep in the affected hemifield. Looking for a better result, in two subjects we tried to place the sector closed to the pupil but patients complained of central diplopia and confusion. A possible alternative (not assessed in the present investigation) is to increase the power of the prism without changing its position.

Therefore the only way the halfmoon sectors can affect the monocular visual field is maximizing the residual sensitivity across the border of the scotoma during steady fixation.

In binocular conditions the visual field turned out to be slightly wider compared to the baseline for all the prism combinations, both before and after the adaptation period. However, despite the high prevalence of the mild improvement, the average effect is not statistically significant. This discrepancy may depend on the consistent variability from the mean values, as the sign of strong inter-individual differences of responsiveness to the prismatic treatment. As a second factor to be considered, the interval occurred from onset of the disease to the prismatic treatment differed in the sample: the longer this interval, the better the results. The reas on for this finding could rely on the presence of hemineglect in the subjects more recently affected. In fact, it is maintained that the occurrence of hemineglect hampers the rehabilitation outcome in hemianopic subjects [32,33,34]. Even if in this study hemineglect has not been assessed, it is likely in subjects with the shortest intervals between onset and examination (like patient 1 and 9). Future investigations are required to make up for this shortcoming.

In addition, the rehabilitative outcome is found to depend on the level of the visual field impairment at baseline, as suggested by the negative correlation between total visual field extent and improvement after adapting to the 30 diopter sectors. The same correlation is found considering the spared hemifield (Figure 7). strong as to increase the overall sensitivity level across the

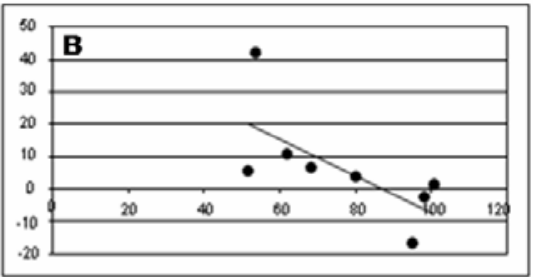


Finally, according to a previous report in post-stroke patients [35] visual recovery would depend also on the mental attitude of the subject, namely on the determination to improve his/her visual condition. This relation should be confirmed, psychological aids are expected to play a key role in the visual rehabilitation program.

In conclusion, our results failed to demonstrate any substantial (therefore statistically significant) a meliorative effect of our halfmoon-designed prismatic sectors on the visual field of hemianopic subjects, and the majority of the recruited patients when asked did not report any quantifiable advantage in wearing the pris $\mathrm{m}$. The failure in our case may depend on the shape of the device and/or on the use of a single sector instead of two pris ms placed in the upper and lower part of the lens carrier, as described by Peli. The slight ameliorative tendency (even if unnoticed by the patients) found in a high percentage of cases suggests that the success of the prismatic rehabilitation of hemianopic patients depends on individual factors and in particular on the onset time of the disease, on the severity of the visual field damage as well as on hemineglect, adaptation capacities and motivation. To better understand which patients may take advantage from the use of the monocular sector prisms and their rehabilitation potential in hemianopia, future researches should focus on such variables and classify the sample accordingly.

The discrepancy between the results obtained in our investigation and the previously findings reported in literature may be due to the prevalence of the aforementioned variables in the recruited samples and to methological differences.Moreover, the prismatic design we adopted can be less effective compared to the other solutions proposed so far.

Undoubtedly the present study suffers from some flaws, like the small size of the sample and the heterogeneity with respect to the onset of the disease or the impairment of the visual field. However, we intended to recruit a general sample representative of the pathological condition in hand.

In addition, binocular kinetic perimetry as commonly performed by using the Goldmann perimeter is not the most suitable technique for research purpose, due to the operator bias and the lack of automated data processing. It is worth to remind that binocular kinetic perimetry is now available also as an automated version, able to rule out these shortcomings in future investigations.

\section{Appendix. Designing the Halfmoon Prismatic Sectors}

Prism sectors of equal area have been designed so as to fit a halfmoon shape. In the figure below the whole presson surface is represented by the elliptical contour. The prism boundary is depicted by BCDM, i.e. the difference between the half-ellipse $\mathrm{BCDH}$ and the circular arc segment BMDH.

Measures:

-horizontal half-axis $=2 \mathrm{~cm}$

-vertical half-axis $=1,2 \mathrm{~cm}$

$-A M=2.3 \mathrm{~cm}$ -angle DÂB $=\frac{\pi}{3}$

BMDH surface is $0,48 \mathrm{~cm}^{2}$ and is calculated as:

$$
\operatorname{Area}(B M D H)=\frac{\pi \cdot(A B)^{2} \cdot \alpha}{2 \pi}-\frac{1}{2} \cdot(A B)^{2} \cdot \operatorname{sen} \alpha
$$

Where $\alpha=\mathrm{DÂ} \mathrm{B}$

$\mathrm{BCDH}$ surface is $3.78 \mathrm{~cm}^{2}$ and is calculated as:

$$
\operatorname{Area}(B C D H)=\frac{\pi}{2} \cdot B H \cdot H C
$$

Finally BCDM (the halfmoon shape) is obtained as $\mathrm{BCDH}-\mathrm{BMDH}$. It measures $3.30 \mathrm{~cm}^{2}$.

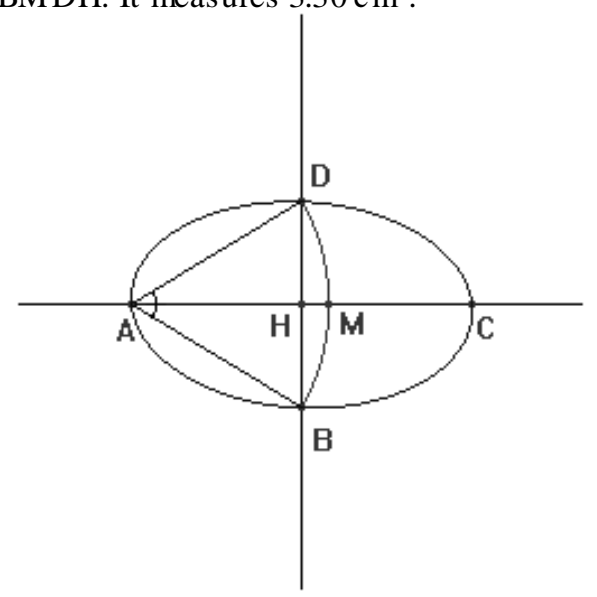

\section{References}

[1] Gilhotra, J.S., Mitchell P., Healey P.R., Cumming R.J., Currie J., "Homonymous visual field defects and stroke in an older population“, Stroke, 33. 2417-2420. 2002.

[2] Huber, A., "Homonymous hemianopia”, Neuroophthalmology, 12. 351-66. 1992

[3] Smith, J.L., "Homonymous hemianopia, a review of one hundred cases", Am J Ophthalmol, 54. 616-623. 1962.

[4] Giorgi, R.G., Woods, R.L., Peli, E., "Clinical and laboratory evaluation of peripheral prism glasses for hemianopia”, Optom Vis Sci, 86. 492-502. 2009

[5] Gottlieb, D.D., "Method of using a prism in lens for the treatment of visual field loss”, U.S. P atent, 4, 779, 972, 19. 1988.

[6] Gottlieb D.D., Freeman P., Williams M., "Clinical research and statistical analysis of a visual field awareness system", $J \mathrm{Am}$ Optom Assoc, 63. 581-588. 1992.

[7] Jose, R.T, Smith, A.J., "Increasing peripheral field awareness with Fresnel prisms”, Rev Optom, 3. 3-37. 1976.

[8] Lee A.G., Perez, A.M., "Improving awareness of peripheral visual field using sectorial prisms” J Am Optom Assoc, 70. 624-628. 1999.

[9] Peli, E., "Field expansion for homonymous hemianopia by optically induced peripheral exotropia”, Optom Vis Sci, 77: 463464. 2000.

[10] Smith JL, Wemer IG, Lucero AJ., "Hemianopic Fresnel prisms”. J Clin Neuro Ophthalmol, 2. 19-22. 1982.

[11] Szlyk, J., Seiple, W., Stelmack, J., McMahon, T., "Use of prisms for navigation and driving in hemianopic patients", Ophthalmic Physiol Opt, 25. 128-135. 2005.

[12] Rossi, P.W., Kheyfets, S., Reding, M.J., "Fresnel prisms improve visual perception in stroke patients with homonymous hemianopia or unilateral visual neglect”, Neurology, 40. 1597-1599. 1990.

[13] Göte, H., Gregersen, E., Rindziunski, E., "Exotropia and panoramic vision compensating for an occult congenital homonymous hemianopia: A case report”, Binocul Vis Eye Muscle Surg Q, 8. 129-132. 1993.

[14] Herzau, V., Bleher, I., Joos-Kratsch, E., "Infantile exotropia with homonymous hemianopia: a rare contraindication for strabismus surgery”, Graefes Arch Clin Exp Ophthalmol, 226. 148-149. 1988. 
[15] Hoit, C.S., Good, W.V., "Ocular motor adaptations to congenital hemianopia. Binocul Vis Eye Muscle Surg Q”, 8. 125-126. 1993.

[16] Levy, Y., Turetz, J., Krakowski, D., Hartmann B, Nemet P. "Development of compensating exotropia with anomalous ret inal correspondence after early infancy in congenital homonymous hemianopia”, J Pediatr Ophthalmol Strabismus, 32. 236-238. 1995.

[17] Bowers, A.R., Keeney, K., Peli, E., “Community-based trial of a peripheral prism visual field expansion device for hemianopia", Arch Ophthalmol, 126. 657-664. 2008.

[18] Woo, G.C., Mandelman, T., "Fresnel prism therapy for right hemianopia” Am J Optom Physiol Opt, 60: 739-743. 1983

[19] Wall, M., Neahring, R.K., Wooward, K.R., "Sensitivity and specificity of frequency doubling perimetry in neuro-ophthalmic disorders: a comparison with conventional automatic perimetry", Invest Ophthalmol Vis Sci, 43. 1277-1283. 2002.

[20] Folstein, MF., Folstein, S.E., McHugh, PR., "Mini-mental state. A practical method for grading the cognitive state of patients for the clinician”, J Psychiatr Res, 12. 189-198. 1975.

[21] Kölmel, H.W., "Visual illusions and hallucinations”. In: Kennard C Editor. Baillière's clinical neurology. Intemational Practice and Research. vol 2, Baillière Tindall Publishers, London, 1993.

[22] Johnson, C.A., Keltner, J.L., "Optimal rates of movement for kinetic perimetry”, Arch Ophthalmol, 105. 73-75. 1987.

[23] Wabbels, B.K., Kolling, G., „Auswirkung unterschiedlicher Prüfgeschwindigkeiten auf die Ergebnisse der kinetischen Perimetrie", Ophthalmologe, 99. 5. 1999.

[24] Ramrattan, RS., Wolfs, RCW., Panda-Jonas, S., Jonas, JB., Bakker, D., Pols, H.A., Hofman, A,, de Jong, PT VM., "Prevalence and causes of visual field loss in the elderly and associations with impairment in daily functioning: the Rotterdam Study", Arch Ophthalmol, 119. 1788-1794. 2001.

[25] Tsai, S.Y., Cheng, C.Y., Hsu, W.M., Su, T.P., Liu, J.H., Chou, P., "Association between visual impairment and depression in the elderly”, J Formosan Med Assoc, 102. 86-90. 2003.
[26] Bruell, J.H., Peszczynski, M., "Perception of verticality in hemiplegic patients in relation to rehabilitation”, Clin Orthop, 12. 124-130. 1958.

[27] Denes, G., Semenza, C., Stoppa, E., Lis, A., "Unilateral spatial neglect and recovery from hemiplegia. A follow-up study", Brain, 105. 543-552.

[28] Kaplan, J., Hier, D.B., "Visuospatial deficits after right hemisphere stroke”, Am J Occup Ther, 36. 314-321. 1982.

[29] Kohler, I., "The formation and transformation of the perceptual world”, Psychol Issues, 3.1-174. 1963.

[30] O’Neill, E.C., Connell, P.P., O’Connor, J.C., Brady, J., Reid, I., Logan, P., "Prism therapy and visual rehabilitation in homonymous visual field loss”, Optom Vis Sci, 88. 263-268. 2011.

[31] Bowers, A.R., Tant, M., Peli, E., "A pilot evaluation of on-road detection performance by drivers with hemianopia using oblique peripheral prisms", Stroke Res Treat, available: http://www.hindawi.com/journals/srt/2012/176806/. 2012.

[32] Gillen, R., Tennen, H., McKee, T., "Unilateral spatial neglect: relation to rehabilitation outcomes in patients with right hemisphere stroke", Arch Phys Med Rehabil, 86. 763-767. 2005.

[33] Katz, N., Hartman-Maeir, A., Ring, H., Soroker, N., "Functional disability and rehabilitation outcome in right hemisphere damaged patients with and without unilateral spatial neglect”, Arch Phys Med Rehabil, 80. 379-384. 1999.

[34] Paolucci, S., Antonucci, G., Grasso, M.G., Pizzamiglio, L., "The role of unilateral spatial neglect in rehabilitation of right braindamaged ischemic stroke patients: a matched comparison", Arch Phys Med Rehabil, 82. 743-749. 2001.

[35] Clark, M.S., Smith, D.S., "The effects of depression and abnormal illness behaviour on out come following rehabilitation from stroke", Clin Rehabil, 12. 73-80. 1998. 